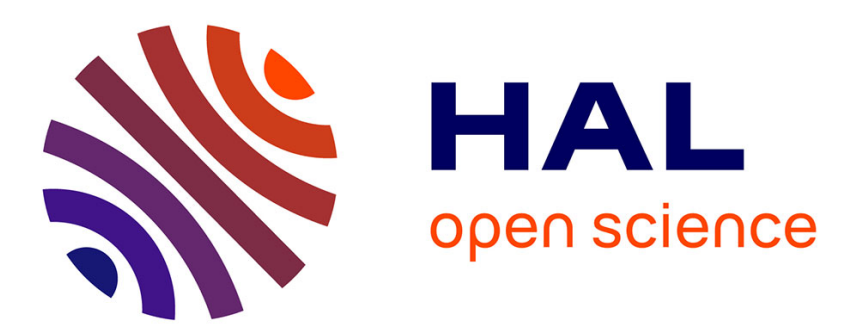

\title{
Gestures' Contribution to Collective Metaphorical Thinking in a Community of Philosophical Inquiry (CPI)
}

Claire Polo

\section{To cite this version:}

Claire Polo. Gestures' Contribution to Collective Metaphorical Thinking in a Community of Philosophical Inquiry (CPI). Studia UBB, 2019, 3 (64), pp.41-64. hal-03583638

\section{HAL Id: hal-03583638 \\ https://hal.science/hal-03583638}

Submitted on 4 Mar 2022

HAL is a multi-disciplinary open access archive for the deposit and dissemination of scientific research documents, whether they are published or not. The documents may come from teaching and research institutions in France or abroad, or from public or private research centers.
L'archive ouverte pluridisciplinaire HAL, est destinée au dépôt et à la diffusion de documents scientifiques de niveau recherche, publiés ou non, émanant des établissements d'enseignement et de recherche français ou étrangers, des laboratoires publics ou privés. 


\section{Gestures' Contribution to Collective Metaphorical Thinking in a Community of Philosophical Inquiry (CPI). Claire POLO}

Abstract: This paper explores an idea expressed by a student discussing where our thoughts come from: "to think we have to move our hands". Such sentence echoes the literature on the role of gesture for thinking. This study also focuses on the collective advancement of reasoning in a CPI. The instructor chooses to conclude by asking each student to suggest an analogy of thinking. This closing sequence reveals how the instructor, through metaphorical gestures, fosters collective awareness of new propositions, and their further elaboration. After characterizing the cognitive models so produced, video analysis is used to follow their collective, verbal and gestural construction along the discussion.

Keywords: dialogical teaching, didactical institutionalization, group reasoning, interactional linguistics, metaphorical gesture.

\section{Introduction}

Grenoble, on a Wednesday afternoon of November 2015: eleven voluntary 12-to-14-yearold students came to their empty middle school building, to meet Professor Sasseville, coming from the University of Laval. Sitting round a circle, they are engaged in a Community of Philosophical Inquiry (hereafter named CPI) about thinking, starting with a first question: "Where do our thoughts come from?". I am one of the few adults then observing this demonstration of CPI. At the speech turn number 207, Arthur, a student, says: "to think we have to move our hands". Let's explore this idea, starting with this concrete situation itself. How do gestures contribute to the advancement of reasoning in a CPI? This day, I leave the room with a great interest for a didactical practice that I had just seen for the first time: Pr. Sasseville ended the CPI by asking each student to define the discussed object by an analogy: “thinking is like...”. Doing so, I saw some students make very relevant cognitive syntheses. Some of the analogies proposed explicitly referred to images used earlier during the discussion and combined them into a more complex picture. By this time, I was working on the collective construction of reasoning in argumentation in small groups, and I immediately got aware of how rich such exchanges were. Moreover, as an interactional linguist, I had just been trained to study multimodal communication, and I was very sensitive to the fact that gesture convey at least as much metaphorical semiotic content as speech does, Streeck even 


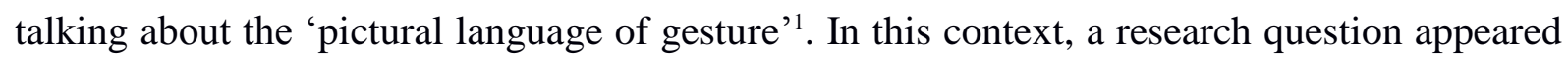
obvious to me: how describing the evolution of participants' metaphorical gestures could make it possible to follow the collective construction of reasoning all along the discussion. More precisely, as we know how helpful they are to actually think ${ }^{2}$, and as this expert practitioner himself chooses to give them a great room at concluding the CPI: how do these gestures take part to the co-construction of cognitive analogies?

In this paper, after specifying the theoretical background of this research (1) and the data analyzed (2), I present my working hypotheses (3). On the basis of the video of this CPI, transcribed and annotated using ELAN software, I could undertake a deep qualitative empirical study, which results are summarized in section 4. I first describe the cognitive analogies mentioned in the closing sequence (4.1) and then retrace the conceptual trajectories through which they got elaborated along the discussion (4.2).

\section{Theoretical background}

Arthur's sentence actually rephrases Goldin-Meadow's book Hearing Gesture: How Our Hands Help Us Think ${ }^{3}$, which constitutes a key research work the role of gesture for learning. After precising the theoretical references corresponding to such idea that our hands help us think, I present, in particular, the opportunities that metaphorical gestures offer for thinking.

\subsection{Our hands help us think}

Taking into account seriously the assumption that our hands help us think implies two things:

1) that gestures take part to thinking; 2) that thinking is a collective activity.

The first point corresponds to considering non-verbal acts not only as serving a communicative function but as actual contributions to thinking, together with other semiotic resources like speech. In this perspective, they do more than supporting speech, they play a great role in the organization of thought itself. Multimodality is apprehended with a 'strong' approach: all the elements provided through diverse modes of communication are combined to build a global message. Even if a great diversity of semiotic resources may be studied, the multimodal combination the most studied and the best known is the speech-gesture system ${ }^{4}$. The second point suggests a shift from traditional individualistic cognitivism to socially extended learning and reasoning, including relational and affective aspects of such

\footnotetext{
${ }^{1}$ Streeck, 2008, p. 298.

${ }^{2}$ Colletta, 2003.

${ }^{3}$ Goldin Meadow, 2004.

${ }^{4}$ McNeill, 1992, Kendon, 2004.
} 
interactions ${ }^{5}$. Education research actually has come through two paradigmatic shifts since a few decades. First, the 'social turn' brought up the idea that learning does occur in an isolated individual brain, but is rather happening through social interaction, both with peers, experts, and with the environment. Stahl even talk about 'group cognition'6. More recently, the 'affective turn' emphasized the affective dimension of learning. At the end of the day, advancement in reasoning is now considered as a tripod process involving all together cognitive, social and emotional aspects ${ }^{7}$. In this respects, part of frontier research in education study 'affective learning together' ${ }^{8}$. Concrete practices associated to such a perspective consists in designing pedagogical situations aiming at dialogic teaching and collaborative learning. Some work aim at characterizing communicative practices that foster high-quality collective reasoning and fruitful sociocognitive discussions. Notably, Mercer and his colleagues defined 'exploratory talk' as the most advanced form of collective reasoning in terms of educational value. A key feature of such practice is that "reasoning is visible in the talk"'. Therefore, making one's reasoning as explicit as possible is not only useful for structuring individual thinking, but also necessary for true collective exploration of problem.

\subsection{Using metaphorical gestures to reason together}

Coverbal gestures may serve a diversity of functions and can be classified as interactive, pragmatic, referential, and discourse-structuring. When the analyst is more interested on the discussed objects rather than on the relations between the people participating to an interaction, the focus is on gestures playing a referential function, those that contribute to the construction of semantic structures. Among non-verbal bodily communicative acts, metaphorical gestures show a specific affordance for collective reasoning for two reasons. First, they play a key role, on the semantic plane, in the referential construction. Metaphorical gestures are referential: each one can be associated to a precise referent used to define analogically the object at stake. For instance, saying 'plant' producing a bottom-up vertical gesture starting associated to opening the hand emphasize a specific aspect of the object 'plant': the action of growing as a seed becomes a flower. More generally, a metaphorical gesture consists in providing a bodily image of a referent, either by drawing or placing it in the gestural space; or by tracing its trajectory; or miming its action ${ }^{10}$. Some metaphorical

\footnotetext{
${ }^{5}$ E. g. Baker, Andriessen, Järvelä, 2013, Menary, 2010, Polo, Plantin, Lund, Niccolai, 2017.

${ }^{6}$ Stahl, 2006.

${ }^{7}$ E. g. Polo, Plantin, Lund, Niccolai, 2017.

${ }^{8}$ Baker, Andriessen, Järvelä, 2013

${ }^{9}$ Mercer, 1996, p 363.

${ }^{10}$ Cosnier \& Vaysse, 1997, Kendon, 2004, McNeill, 1992.
} 
gestures directly refer to a concrete referent, as drawing a woman shape to refer to a specific person. Other metaphorical gestures exploit concrete imagery to apprehend an abstract concept ${ }^{11}$. For example, saying that something is complex making a hand gesture above one's head refers to the concrete vision of something bigger, used to express the feeling of not being 'big enough' to deal with the complexity of the issue. Such abstract metaphorical gestures are of a particular interest since they make it possible to see how an object which is being learnt or thought about is gradually shaped into one or several cognitive model(s) during a discussion, through metaphorical trial and error ${ }^{12}$.

Second, metaphorical gestures are great resources for collective reasoning thanks to the fact that they display a specific image of a discourse object, which is never neutral on the argumentative plane. Actually, such gestures embody metaphorical thinking, which is a core process based on two fundamental argumentative scheme: definition/categorization and analogy. By providing images of discourse objects associated with specific positions, metaphorical gestures play a crucial role in what Grize calls 'natural logic':

I understand argumentation as considering the interlocutor, not as an object to be manipulated; but as an alter ego to share a vision with. Acting on him is trying to modify the diverse representations that we think that he/she has, emphasizing some aspects of things, masking others, presenting new ones, and all that thanks to an appropriate schematization. ${ }^{13}$

Thinking, in the terms of the 'natural logic', would only occur building and exploiting linguistic metaphors serving as cognitive models. Such schematizations are never neutral on the argumentative plane, since they highlight specific aspects of the discourse object, associated to the claim being defended:

Natural logic can be defined as the study of logico-discursive operations that make it possible to build and rebuild a schematization. The double adjective is here to highlight the fact that they are operations of thought, but only as long as they are expressed through discursive activities ${ }^{14}$.

\footnotetext{
${ }^{11}$ Cienki \& Muller, 2008, McNeill, 1992.

12 E. g. Polo, Lagrange-Lanaspre, 2019.

${ }^{13}$ Own translation from the French: "Telle que je l'entends, l'argumentation considère l'interlocuteur, non comme un objet à manipuler, mais comme un alter ego auquel il s'agira de faire partager sa vision. Agir sur lui, c'est chercher à modifier les diverses représentations qu'on lui prête, en mettant en évidence certains aspects des choses, en en occultant d'autres, en en proposant de nouvelles et tout cela à l'aide d'une schématisation appropriée." (Grize, 1997, p. 40).

${ }^{14}$ Own translation from the French : "La logique naturelle peut être définie comme l'étude des opérations logicodiscursives qui permettent de construire et de reconstruire une schématisation. Le double adjectif est là pour souligner le fait que l'on est en présence d'opérations de pensée, mais dans la mesure seulement où celles-ci s'expriment à travers des activités discursives.” (Grize, 1997, p. 65).
} 


\section{Pedagogical situation and dataset}

The dataset is a video record of a demonstration of Community of Philosophical Inquiry (now CPI) led by M. Sasseville, Professor at Laval University (Canada), in a French middle school, on Novembre $18^{\text {th }} 2015$. The involved eleven students are aged 12 to 14 and are used to practicing CPI with their teachers. The whole session is observed by a dozen of people including the students' teachers, researchers and practitioners. The discussion was fully recorded using a $360^{\circ}$ camera placed in the middle of the circle of the participants. lle est enregistrée à l'aide d'une caméra $360^{\circ}$ placée au centre du cercle des participants. The students have previously read the third chapter of a French translation of Harry Stotlemeier's Discovery ${ }^{15}$, and elaborated several questions which were transmitted to Sasseville. After reading them all outload, he suggests the students to start the conversation with one of them, without explaining why he chooses it: "where do our thoughts come from?”.

\subsection{A situation of exception}

As a demonstration, such situation is not usual neither for the students nor for the facilitator. It is the first time that they meet each other, and the students have prepared a small piece of paper with their name in front of them, so that Sasseville can identify them. The session is very formally introduced by the director of the school and the responsible of the research team who invited the Canadian professor to Grenoble. Nothing is said about the observers who are strangers to the students. On Wednesday afternoon, the school is usually closed, and this special room, the auditorium, is the only one that is not empty, the students and the facilitator sitting round a semi-circle 'on the stage', facing the audience of the observers. Sasseville arrived about 30 minutes late, due to transport issues, and the whole, extracurricular exercise is not to be assessed by a grade. We are truly in a situation of exception, breaking the school routine: time and punctuality, spatial arrangement, ratio children/adults, etc.

\subsection{A consolidated pedagogical practice}

Still, a number of elements nevertheless converge to define the activity as a consolidated pedagogical practice. First, the CPI is taking place in the school building, and the students are used to do philosophical inquiry with the teachers observing the demonstration. They actually prepared the session with them, and they very easily welcome Sasseville as an expert facilitator. Sasseville himself takes the time to explicitly refer to this previous work done with the teachers, starting the discussion on the basis of the questions raised by the students'reading. On their side, for being here in such setting, the students can be considered

\footnotetext{
${ }^{15}$ Lipman, 1978.
} 
as expert participants two. One of them feels confident enough with the practice to suggest Sasseville, as if he were reminding him of an obvious rule, to give them a few minutes to individually think about the problem in silence before they start talking, which he accepts directly. Students and facilitator therefore recognize each other as 'connoisseurs' of a common practice. The discussion then starts quite freely: the facilitator distributing speech turns, reformulating or synthesizing students' propositions, relaunching the inquiry when he feels it necessary; the students raising their hand to bring examples, attempts of definitions and conceptual distinctions.

The instructor chooses to conclude by asking each student to suggest an analogy of thinking. Such closing sequence consists in a double activity both of what the French didactics would call devolution and institutionalization. The student, treated as a 'valid interlocutor' ${ }^{16}$, is asked to make explicit what he considers the salient features of the concept of thinking, using a metaphor. Here relies a didactical devolution: the student is made responsible of his learning, thanks to the creation of an adidactical moment aiming at converting the taught knowledge into the student's knowledge ${ }^{17}$. On the same time, the study of the interactional schema of the closing sequence reveals that Sasseville is also here doing what Brousseau named institutionalization $^{18}$. Typically, each proposition made by a student (speech turn $\mathrm{N}$ ) is surrounded by interventions of the facilitator, as indicated in figure 1: he allows the student to talk (turn N-1), and, ratify, or even rephrase the proposition after it was uttered (turn $\mathrm{N}+1$ ). At $\mathrm{N}+1$, the facilitator may also ask clarifications of precisions, then driving the interaction back to the N-1 stage again.

Figure 1. Interactional schema surrounding each student proposition during the closing sequence.

At speech turn $\mathrm{N}+1$, the facilitator reacts briefly, mostly producing verbal ratifications. But doing so, he very often produce simultaneous coverbal metaphorical gestures that embody, and the analogies made by the students, and sometimes gesturally elaborate on them. Such gestural activity of the facilitator seems to contribute to the institutionalization of students' propositions. At speech turn $\mathrm{N}+1$, the facilitator decontextualizes and depersonalizes the soproduced concept again, in order to let the students recognize it as a valuable useful

\footnotetext{
${ }^{16}$ Lévine, 2007.

${ }^{17}$ Rouchier, 1991.

${ }^{18}$ Brousseau, 1984.
} 
knowledge. As a whole, this closing sequence appears as a typical instance of dialogic teaching, an interactional genre that the facilitator masters very well, demonstrated here through a consolidated pedagogical practice.

\subsection{Dataset}

Even if I observed myself the whole CPI, taking some useful notes to characterize the situation, analyzing how metaphorical gestures contribute to the collective construction of cognitive analogies requires specific technical equipment. Such study was made possible thanks to the generous sharing of the full video record and verbal transcript of the discussion made by the members of the Phileduc project of the LiDiLEM laboratory.

I started with a deep analysis of the closing sequence, in order to characterize the cognitive models used to end the CPI. I then used video analysis to step back and follow how such images were collectively built all along the discussion, both verbally and gesturally. To do so, I had to import parts of the video in ELAN software, in order to transcribe metaphorical gestures and synchronize them to verbal transcript. I did so systematically both for the closing sequence (5 min $35 \mathrm{~s}$ ) and all the excerpts involving similar analogies during the previous discussion, constituting a collection of $2 \mathrm{~min} 20 \mathrm{~s}$. Last but not least, in this paper, I also present the analysis of a $21 \mathrm{~s}$ excerpt illustrating how the facilitator react to a proposition made by Ulrick at the very beginning of the CPI ( $7^{\text {th }}$ minute).

\section{Working hypotheses}

Many empirical pieces studied the role of gestures in teaching. Their results converge on two things: most experienced teachers gesture more ${ }^{19}$, and using gestures makes teaching more efficient ${ }^{20}$. An interpretation of such findings relies on the idea that coverbal gesturing would provide the students with a diversity of representations of a concept, complementary to verbal teaching ${ }^{21}$. In the present situation, the matter is not to provide explanations to the students, but to foster the emergence of diverse representations of the concept in the discussion, in a way that make them visible and understandable enough so that the whole group can appropriate and explore them.

\subsection{Didactical hypothesis: making reasoning explicit}

A first, didactical working hypothesis consists in apprehending the facilitator's abundant metaphorical gestures along the CPI focusing on their didactical functions. Such analytical perspective implies that the studied gestures were actually produced to serve the associated

\footnotetext{
${ }^{19}$ Caswell \& Neill, 1993.

${ }^{20}$ E. g. Alibali et al., 2013, Perry, Berch \& Singleton, 1995, Polo, Colletta, in press.

${ }^{21}$ Singer \& Goldin-Meadow, 2005.
} 
didactical functions, rather than just instantiating gestural contagion or empathic communication not related to the pedagogical nature of the situation.

At first sight, the facilitator's rich gestural interventions in $\mathrm{N}+1$ turns is directed to a single specific student, falling into individualized teaching. We can hypothesize that, when he reacts to a student's proposition by asking him to specify his thought producing metaphorical gestures, he is doing a kind of 'gestural maieutics'. The student is then led to confirm or infirm the gestures suggested by the facilitator as rephrasing his proposition, and, doing so, to make his analogy more explicit or to further elaborate on it. Somehow, the facilitator provides the student with a magnifying glass of the proposition made at turn $\mathrm{N}$, in order to help him/her think more about it and potentially refining it.

Still, it would be simplistic to consider only this individual didactical function of the facilitators' gestures. Actually, when asking such clarifications, Sasseville very often invites the student to position his/her own proposition regarding other analogies previously made by other students, either by explicitly mentioning them verbally, or by reusing the associated gestures. Indeed, one of the key features of the didactical discourse is to be polydirected, gestures playing an essential role in setting what Azaoui called the 'enunciative ubiquity' of the teacher ${ }^{22}$. The metaphorical gestures produced by the facilitator during this discussion should therefore be understood as being also directed to the rest of the group of students, to the CPI as a whole. In this perspective, Sasseville's gestural translation of each proposition may also serve the purpose of emphasizing the specificities of each analogy and making it intelligible to others.

\subsection{Linguistic hypothesis: the co-constructing gestural metaphors}

The above mentioned didactical hypothesis is complemented by a linguistic hypothesis: if the didactical function of metaphorical gestures is to make reasoning visible so that it becomes collective, then there must be linguistic markers of such collective construction. All along the discussion, it must be possible to follow the marks of the emergence and evolution of a given cognitive analogy. More specifically, such trajectory of the co-construction of metaphors is then likely to be gesturally characterized.

When the corresponding linguistic qualitative approach is associated to the pedagogical context studied, this second hypothesis can be synthesize as follows: the trajectory of a given cognitive analogy made by a student during the CPI highly depends on whether and how it is

\footnotetext{
${ }^{22}$ Azaoui, 2014.
} 
gesturally rephrased by the facilitator. As a working proposition, I hypothesize that the more a proposition is emphasized by the facilitators' gestures, the more the students will reuse it.

\section{Results}

To better expose the heuristic approach that I followed, I present the results in a specific reverse chronological order, which corresponds to the progress of the analytical steps undertaken. As a result, I start with the analysis of the closing sequence, before getting to the trajectories of collective elaboration on the concept of thinking all along the discussion, using metaphorical reasoning.

\subsection{Closing a CPI with sharing images}

The closing sequence must be analyzed taking into account the conversational history, students' contributions therefore appearing as more or less innovative or redundant. Table 1 inventories students' propositions made during this closing sequence, in a chronological order. This synthesis also includes the names of the locutors, how innovative the proposition is (first occurrence; elaborating on a metaphor already used during the closing sequence; elaborating on a metaphor already used during the CPI), whether or not it is gesturally rephrased by the facilitator; and whether or not it is reused during the closing sequence.

Table 1. Cognitive models proposed during the closing sequences: degree of innovation and becoming.

The students used 9 analogies during the closing sequence, only 2 of which being totally new and not previously mentioned in the CPI : the Milky Way (Elias) and the cloud (Ulrick). Most students chose analogies that have already been discussed: to dream (Iacob), to use files, cogwheels (Jean-Luc), to reflect (Sabrina), to remember (Evan), a blurred picture (Ulrick), to imagine (Sofia). One student repeats a proposition that has just been made during the closing sequence, and two other students keep silent.

The instructor, through metaphorical gestures, help the students specify the analogy that they are creating, although he does not systematically produce such gestures at N+1-type speech turn. He gestures more for more innovative propositions (the Milky Way, the cloud). The first student interventions of the sequence, which formalize analogies previsouly mentioned during the discussion, are generally gesturally rephrased by Sasseville (to dream, cogwheels, blurred 
picture). Table 2 describes the metaphorical gestures used by Jean-Luc and the facilitator at turns 405-406, when discussion the proposition of the 'cogwheels model'.

Table 2. The facilitators' gestural rephrasing of a student proposition: the cogwheels example.

On the contrary, the facilitator does not gesturally react to the interventions repeating the propositions that have just been mentioned. Here, Sasseville's gestural activity seems to actually serve a didactical function, helping the students discriminate and value the propositions likely to enrich the most the collective reasoning, for being the most innovative. Doing so, he highlights them and fosters their collective appropriation by the whole CPI. Indeed, such facilitator's gestural rephrasing is correlated to the reuse of the propositions: when a proposition is not gesturally rephrased by Sasseville, it disappears from the discussion, except in two cases: to remember and a blurred picture. This result tends to validate the first hypothesis. The facilitator's gestural rephrasing of the analogies actually plays a function of elicitation that favors their sharing among the students.

Semantically, this closing sequence is also the moment when cognitive models, in the sense of the natural $\operatorname{logic}{ }^{23}$, are made explicit. Such images give a global picture of the different ways in which the philosophical issue at stake is apprehended. Tables 3 and 4 present the 9 cognitive models then mentioned and their key features. The descriptive categories were not a priori designed but rather empirically built on the basis of the dataset. Each cognitive model was defined along 5 characteristics at most: 1) fundamental units of thought; 2) nature more or less dynamic or static of thought elaboration; 3) internal structure of thoughts; 4) localization of thoughts; 5) size of the model. For each model, students' corresponding utterances are transcribed. Due to space limitation, coverbal gestures are only mentioned when they are not redundant with verbal information. They appear with small pictures for the information exclusively conveyed gesturally.

Table 3. Characteristics of the cognitive models to dream, the Milky Way, to use files, and cogwheels used by the students during the closing sequence.

For instance, the localization of thoughts in the subject's head, in the 'to dream' model, is gesturally expressed by the facilitator at turn 400. Similarly, in the 'cogwheels model', the

\footnotetext{
${ }^{23}$ Grize, 1997, p. 65.
} 
causal reasoning is verbally expressed but the cyclic dimension of the process only appears un gestures, first by the student's one-hand circular gesture, and later by the two-hand gesture produced by Sasseville. He is also responsible for conferring a big size to the cogwheel model by drawing a big circle with his hand when elaborating on the clock metaphor. Nourra, who use two models within a single speech turn, to remember and a blurred picture, also only gesturally localizes thinking as an activity occurring in the subject's head, producing a righthand abstract pointing to her own head.

Table 4. Characteristics of the cognitive models to reflect, to remember, a cloud, a blurred picture and to imagine used by the students during the closing sequence.

The five characteristics studied are not necessarily specified for each model, at least during this closing sequence. 'To reflect' is mentioned without any description. 'To imagine' is only presented as a dynamic process implying an active subject building up images. The 'to dream' model is described as a process consisting in pictures coming to the head. The proposition 'to remember' also corresponds to a phenomenon involving images as fundamental smaller units and taking place in the head, based on a double process of recording and replaying. The size of these models is not mentioned. On the contrary, the cloud model is not presented as made of smaller units, but rather apprehend thought as a volatile thing, likely to fly away at any time... an activity without materiality. The Milky Way model is described as an immense system of systems, the planets standing for the units of thought. Finally, to use files is the only model characterized along all these 5 aspects. Thoughts, or files, as fundamental units, can either be created randomly or from a previous already existing file. Such big system has a well-structured chronological intern organization, located inside the subject's head, where creation and displacement of files, either intentional or random, occurs. Last but not least, the 'cogwheels model' emphasizes cyclic causality, represented as the intertwining of thoughts into a big machine.

Even if each model exploit a specific metaphor to apprehend the concept of thinking, several models share common characteristics among these 5 points: images as fundamental units; a chronological or causal relation between thoughts; considering thinking as an activity occurring inside the subject. This is not surprising: the students are formulating such propositions after more than 40 minutes of common discussion on the topic. 


\subsection{Conceptual trajectories: collective elaboration of gestural metaphors}

Linguistic video analysis reveals how these cognitive models were built and refined all along the CPI. It enables the analyst to see how they are co-constructed, shared and transformed both verbally and gesturally in the interaction, with a great participation of the facilitator, and sometimes of student who do not mention them during the closing sequence. Such study of conceptual trajectories through the co-construction of gestural metaphors was only applied to 5 of the 9 models. It was impossible to do on the two models emerging during the closing sequence for the first time: the cloud and the Milky Way. I also set apart the models to dream and to reflect, because they actually had a specific status, as they were used during the CPI to bring the students to do distinctions of the form: 'to think is not the same as to dream because...' Figure 2 shows the chronological order of apparition and reuse of the 5 models all along the CPI: to remember, a blurred picture, to imagine, cogwheels, to use files.

Figure 2. Order of emergence and reuse of the 5 cognitive models during the CPI.

This figure makes visible that the development of one model is not linear and relies on several students, helped by the facilitator. This result confirms that there is such thing as a collective construction of the cognitive analogies. In order to study the specific role played by gestural metaphors in such conceptual trajectories, I created five collections of all the gestures associated, along the CPI, with each one of the five models. The linguistic hypothesis is here validated: there are gestural specificities corresponding to the use of specific cognitive analogies. Information gesturally conveyed precise the five models as follows:

- to remember: images coming from the outside, getting up into someone's head (44 s collection);

- blurred picture: the thought is a flow of blurred images (10 s collection);

- to imagine: internal mental images coming out of the subject's head ; (15 s collection);

- cogwheels: each thought is a cogwheel causally linked to another one (17 s collection);

- to use files: we can create files (thoughts), use them, modify them, delete them, retrieve them (53 s collection).

Focusing on gestures makes particularly visible a strong and binary opposition between two distinct models of thinking that the discussion sometimes alternated dialectically between: to remember and to imagine. A look at the facilitator's behavior reveals that he plays a great role in making the above-mentioned dialectical opposition clear, specifically using metaphorical gestures. He does so when synthesizing the expressed ideas and relaunching the discussion by 
minutes 15,18 and 28 of the recorded video track. But this opposition is institutionalized even before, as a reference difficult to overcome, on the basis of which the students are pressed to position themselves all along the CPI. For instance, a short dialogue between Ulrick and Sasseville, on the $8^{\text {th }}$ and $9^{\text {th }}$ minutes of the video, shows how prevalent this opposition is.

Table 5. Between maïeutics and gestural overinterpretation: facilitator dealing with 'the opposite of the outside'.

Ulrick says that some thoughts might come to the subject due to the context, even though they are not relevant in the ongoing situation. Sasseville reacts to this contribution as if it were a vague proposition to be clarified. To help Ulrick do so, the facilitator suggests a reformulation including many gestures, inviting him to precise his idea within the binary framework opposing the recorded thoughts coming from the outside (to remember) and the thoughts created inside the subject (to imagine). But Ulrick resists and maintains that the 'inverse of the outside' does not equals 'the inside', and produces a cyclic gesture showing that the thought is then coming from the 'outside', the context to which it is nevertheless somehow opposed. Doing so, Ulrick literally explodes the binary categorization serving as a reference for the discussion, and this overall short dialogue leave the impression of a great misunderstanding. Still, it is worth mentioning that the last cognitive model to be introduced (to use files) is a more complex one that conciliates these two approaches. Jean-Luc actually explains that the thoughts-files can either be created 'randomly', like memories, or 'mixing others', like pieces of one's imagination. (cf. table 3). Does such interesting proposition result from the student's will to resist the binary opposition scheme of the facilitator? Or, on the contrary, does it appear thanks to the didactical emphasis put by the facilitator on this dialectical opposition as a first stage of conceptualization to be overcome?

\section{Discussion: gestural echoing and collective reasoning}

This study emphasizes that metaphorical gestures are at the heart of collective reasoning in CPI. On the didactical plane, they play a maieutic role to help each student clarify his/her proposition, either verbally or by 'correcting' the gestural rephrasing suggested by the facilitator. Besides, the facilitator's gestural work should be understood as a polydirected discourse, also aiming at driving the other members of the CPI's attention to innovative ideas, fostering their future reuse and further elaboration. In this perspective, it would be helpful to 
conduct explicitation interviews with facilitators, on the basis of the video record of discussions that they led, in order to help them gain awareness of the impact of their gestures and to confirm that they gestured more when dealing with propositions that they thought more likely to enrich the philosophical inquiry. In general, it seems that using metaphorical gestures can be a good practice to recommend, specifically during shorts syntheses or relaunching the discussion, still keeping in mind to avoid the artificial introduction of systematic emblems that might contradict the careful listening and rephrasing of students' idiosyncratic productions. At the end of the day, the more the concepts tend to be 'pre-thought' by the facilitator, the more difficult it is to him/her to understand and value really striking, disruptive propositions as 'the opposite of the outside'. Paying attention to such contributions falling into the kairos also counts much because the cognitive model under elaboration are very permeable to each other: several of the 9 final analogies proposed by the students share some key features.

\section{References}

Alibali, M. W., Young, A. G., Crooks, N. M., Yeo, A., Wolfgram, M. S., Ledesma, I. M., Nathan, M. J., Church, R. B., Knuth, E. J., "Students learn more when their teacher has learned to gesture eff ectively", in Gesture, 1(2), 2013, John Benjamins Publishing, 210 233.

Azaoui, B., “Analyse multimodale de l'agir professoral et degré de granularité de traitement. Réflexions méthodologiques", in Lidil 49, 2014, OpenEdition, 17-32.

Baker, M., Järvelä, S., \& Andriessen, J. (Eds), Affective Learning Together: Social and Emotional Dimensions of Collaborative Learning, Routledge, 2013.

Brousseau, G., Le rôle du maître et l'institutionnalisation, in Recueil de textes et comptes rendus ; IIlème école d'été de didactique des mathématiques, Olivet (Orléans), 1984, pp. 43-47.

Caswell, C., \& Neill, S., Body language for competent teachers, Routledge, 1993.

Cienki, A. \& Müller, C., Metaphor and Gesture. Amsterdam/Philadelphia: John Benjamins Publishing, 2008.

Colletta, J.-M., "Philosopher avec les mains ?”, in E. Auriac-Slusarczyk \& J.-M. Colletta, Les atlacobers de philosophie: une pensée collective en acte, Clermont Ferrand: Presses universitaires Blaise Pascal, 2013, pp. 289-310. 
Conne, F., "Savoir et connaissance dans la perspective de la transposition didactique", in Recherches en Didactique des Mathematiques, 12 (2.3), 1992, La Pensée Sauvage, 221270.

Cosnier, J. \& Vaysse, J., "Sémiotique des gestes communicatifs", in Nouveaux Actes Sémiotiques 9(52-53-54), 1997, Unilim: Presse de l’Université de Limoges, 7-28.

Goldin-Meadow, S., Hearing gesture: How our hands help us think. Cambridge, MA, Harvard University Press, 2004.

Grize, J. B., Logique et langage, Ophrys, 1997 [1990].

Kendon, A, Gesture: Visible action as utterance, Cambridge University Press, 2004.

Lévine, J., "La notion de «monde philosophique des enfants »: utopie ou nécessité ? Présupposés, place, limites ?”, in M. Tozzi, Apprendre à philosopher par la discussion, De Boeck Supérieur, 2007, pp. 93-107.

Lipman, M., La Découverte de Harry Stottlemeier, Paris: J. Vrin, 1978.

McNeill, D., Hand and Mind: What Gestures Reveal about Thought, University of Chicago Press, 1992.

Mercer, N., "The quality of talk in children's collaborative activity in the Classroom", in Learning and instruction, 6(4), 1996, Elsevier, 359-377.

Perry, M., Berch, D. B., Singleton, J. L., "Constructing shared understanding: The role of nonverbal input in learning contexts", in Journal of Contemporary Legal Issues, 6, 1995, University of San Diego, 213-235.

Polo, C., Colletta, J.-M., “The Multimodal Mediation of Knowledge: instructors' explanations in a scientific café", in Multimodal Communication, in press, De Gruyter.

Polo, C., Lagrange-Lanaspre, S., "Metaphorical Reasoning Together: Embodied Conceptualization in a Community of Philosophical Inquiry", in K. Lund, G. Niccolai, E. Lavoué, C. Hmelo-Silver, G. Gweon, M. Baker, A Wide Lens: Combining Embodied, Enactive, Extended, and Embedded Learning in Collaborative Settings, Proceedings of the $13^{\text {th }}$ Conference on Computer-Supported Collaborative Learning (1), 2019, pp. 424-431.

Polo, C., C. Plantin, K. Lund, G. P. Niccolai, "Group Emotions in Collective Reasoning: a Model”, in Argumentation 31(2), 2017, Springer, 301-329.

Rouchier, A, Étude de la conceptualisation dans le système didactique en mathématiques et informatique élémentaires, Thèse d'état, Université d'Orléans, 1991.

Stahl, G., Group cognition, MIT Press, 2006.

Streeck, J., "Depicting by gesture”, in Gesture 8(3), 2008, John Benjamins Publishing, 285301. 
Singer, M. A. \& Goldin-Meadow, S., "Children learn when their teacher's gestures and speech differ”, in Psychological Science 16(2), 2005, Sage Publications, 85-89. 